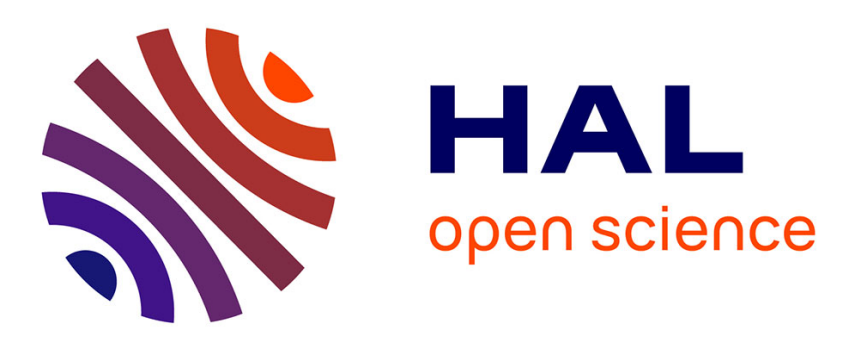

\title{
ULTRASONIC PROPERTIES IN BISPHENOL A-BASED THERMOSETS CURED WITH MNA AND ALIPHATIC DIAMINE
}

\author{
M. Matsukawa, Y. Tanaka
}

\section{- To cite this version:}

M. Matsukawa, Y. Tanaka. ULTRASONIC PROPERTIES IN BISPHENOL A-BASED THERMOSETS CURED WITH MNA AND ALIPHATIC DIAMINE. Journal de Physique IV Proceedings, 1992, 02 (C1), pp.C1-763-C1-766. 10.1051/jp4:19921166 . jpa-00251126

HAL Id: jpa-00251126

https://hal.science/jpa-00251126

Submitted on 1 Jan 1992

HAL is a multi-disciplinary open access archive for the deposit and dissemination of scientific research documents, whether they are published or not. The documents may come from teaching and research institutions in France or abroad, or from public or private research centers.
L'archive ouverte pluridisciplinaire HAL, est destinée au dépôt et à la diffusion de documents scientifiques de niveau recherche, publiés ou non, émanant des établissements d'enseignement et de recherche français ou étrangers, des laboratoires publics ou privés. 


\title{
ULTRASONIC PROPERTIES IN BISPHENOL A-BASED THERMOSETS CURED WITH MNA AND ALIPHATIC DIAMINE
}

\author{
M. MATSUKAWA and Y. TANAKA \\ Government Industrial Research Institute, Osaka 1-8-31, Midorigaoka, Ikeda, Osaka 563, Japan
}

\begin{abstract}
Résumé.-L'influence des différents types de liaisons des époxides de bisphenol A ont été étudiées sur leors propriétes ultrasoniques. Ces liaisons engendrent une $\beta$ relaxation et une diminution de l'elasticité des résines a l'état congelées.

Abstract.- In the bisphenol A-based epoxides, effects of crosslinking on the ultrasonic properties were studied. Crosslinking gives rise to the $\beta$ relaxation and the decrease of elasticity and density in the glassy state resins.
\end{abstract}

\section{INTRODUCTION}

In spite of the outstanding characteristics and usefulness of epoxides in the glassy state, most studies have employed investigations of the rubbery state, owing to the ease of obtaining low frequency dynamic and thermal measurements(ref./1//2/). This is because such measurements are not appropriate for sensitive analysis of the high elasticity in the glassy state, in which network structures are freezed. There is, however, a strong necessity for non-destructive testing in thermosets and thermo-plastics, requiring the detailed analysis of the elasticity in the glassy state(ref./3/). In addition, some recent studies have discussed the contribution of sub relaxations, in the glassy state to the impact strength(ref./4/). So in this work, we have studied the effect of polymerization and crosslinking in glassy state resins, on the elasticity, with especial consideration to the results from the ultrasonic measurements in the $\mathrm{MHz}$ range.

\section{MATERIALS AND TECHNIQUES}

The networks in resin were formed by the condensation of the diglycidyl ether of bisphenol A-based epoxy resin (Epon 828, Shell Chemical Co.) with curing agents. The agents used in this study were Diaminobutane(BDA) and methylnadic anhydride(MNA) catalyzed with imidazole.

The procedure for preparing the samples is given below. For the first preparation of resins, the amount of BDA used was 50-100\%, where the stoichiometric amount of BDA to Epon 828 at $100 \%$ reflects a ratio of $1: 1$. The mixture was held in vacuum for degassing to eliminate void formation and cured overnight at $0-5^{\circ} \mathrm{C}$. It was, then, held for $1 \mathrm{hr}$ at $60^{\circ} \mathrm{C}$, $3 \mathrm{hr}$ at $100^{\circ} \mathrm{C}$ and $3 \mathrm{hr}$ at $150^{\circ} \mathrm{C}$. For MNA, $88-100 \%$ of the stoichiometric amount was used with a little imidazole. The mixture was heated for $1 \mathrm{hr}$ at $100^{\circ} \mathrm{C}, 5 \mathrm{hr}$ at the range of 100 to $200^{\circ} \mathrm{C}$. All samples were gradually cooled to room temperature.

A pulse technique was used for measuring ultrasonic properties. In this technique, the specimen and two transducers are immersed in water or silicone oil, which are controlled from 10 to $100^{\circ} \mathrm{C}$ to an accuracy of $0.5^{\circ} \mathrm{C}$. Ultrasonic pulses are sent from one PZT transducer to the other and the longitudinal wave velocities could be found using the observed difference in time of flight with and without the sample. For longitudinal attenuation, wide band transducers whose nominal frequencies were $10 \mathrm{MHz}$ were also used in addition to the PZT transducers. The pulses received by the wide band transducers were digitized and analyzed in the frequency region using Fast Fourier Transform 
with a personal computer. The averaged resulting spectra from specimens of different thickness yielded the attenuation as a function of frequency. Thermal expansion in specimen thickness was of course considered in these measurements and calculations.

The dynamic storage modulus and loss modulus were measured at low frequencies over the temperature range of -150 to $250^{\circ} \mathrm{C}$ by a dynamic viscoelastometer(VIBRON) built by ORIENTEC. The dielectric permittivity and linear thermal coefficient of resins were also measured respectively using an impedance gain phase analyzer, built by HP and a thermo-mechanical analysis system(TMA) built by RIGAKU.

\section{RESULTS AND DISCUSSION}

Figure 1 shows the typical plots of the dynamic storage modulus $\mathrm{E}^{\prime}$ and loss modulus $\mathrm{E}^{\prime \prime}$ against temperature measured at $110 \mathrm{~Hz}$. In general, $\mathrm{E}^{\prime}$ decreases dramatically at the glass transition which reflects the changes of the state from glassy to rubbery. E" also shows two peaks $\alpha, \beta$ which respectively results from main $\alpha$ and sub $\beta$ relaxations.
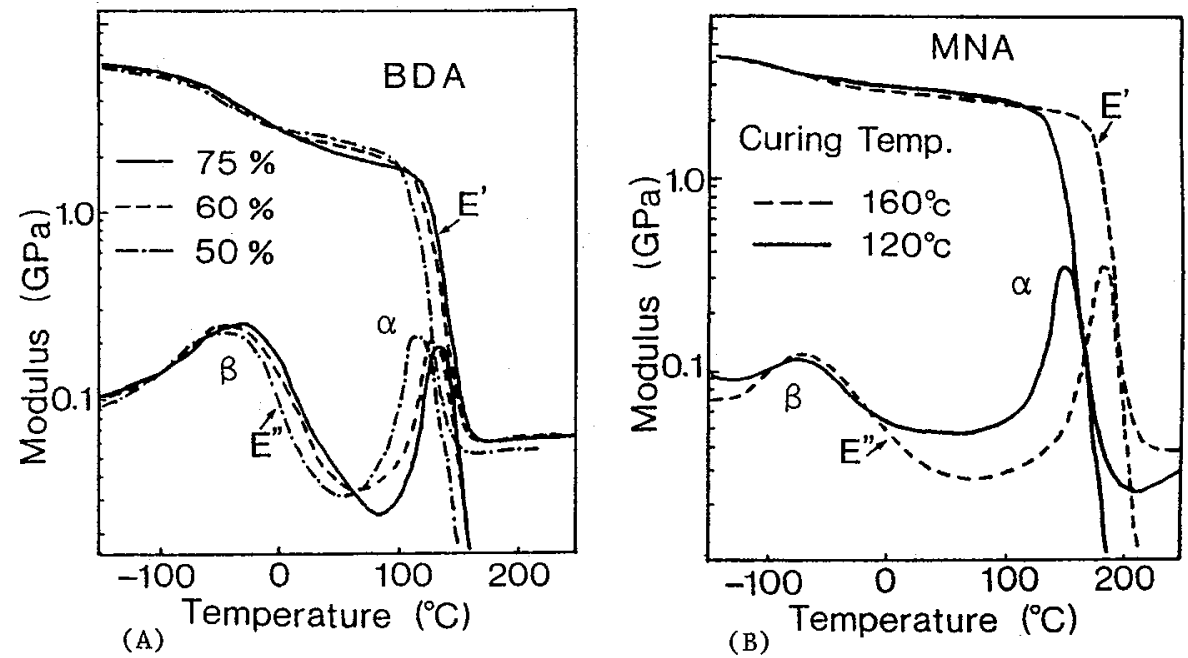

Fig.1 Dynamic storage modulus $E^{\prime}$ and loss modulus $E^{\prime \prime}$ of resins measured at $110 \mathrm{~Hz}$.

Table 1 Ta of cured resins at $110 \mathrm{~Hz}$.

A) Resins cured with MNA.

\begin{tabular}{|c|c|c|c|c|c|c|}
\hline & \multicolumn{6}{|c|}{ Curing Temperature $\left({ }^{\circ} \mathrm{C}\right)$} \\
\hline & 100 & 120 & 140 & 160 & 180 & 200 \\
\hline Curing $88 \%$ & 122 & 150 & 170 & 182 & 175 & 173 \\
\hline Agent $94 \%$ & 124 & 150 & 169 & 180 & 183 & 184 \\
\hline $100 \%$ & 123 & 149 & 170 & 184 & 196 & 198 \\
\hline
\end{tabular}

B)Resins cured with BDA.

\begin{tabular}{|c|l|}
\hline Curing Agent & $\mathrm{T} \alpha\left({ }^{\circ} \mathrm{C}\right)$ \\
\hline $50 \%$ & 127 \\
$60 \%$ & 130 \\
$75 \%$ & 133 \\
$100 \%$ & 138 \\
\hline
\end{tabular}

As shown in Table 1, high curing temperature and stoichiometric amount of curing agents cause a rise in the $\alpha$ peak at $110 \mathrm{~Hz}(\mathrm{~T} \alpha)$. This reflects the advance of crosslinking and the improvement of high temperature stability. In MNA cured resins, the temperatures of $\alpha$ peak at $110 \mathrm{~Hz}$ were almost always higher than those in BDA cured resins. These differences, caused by bonding conditions between resin and curing agents, also result in the strength of the low temperature loss peak $\beta$. For the $\beta$ peak, the loss moduli $E^{\prime \prime}$ varies slowly over a wide temperature range with respect to the distribution of relaxation times in the glassy states. This peak has been reported to result from a particular mode of motion in side groups, owing to crosslinking (ref./5/). The key results here are the difference in the strength of $\beta$ peak between BDA and MNA cured resins. As can be seen in 
Figure 1 , the $\beta$ peak in BDA cured resins are much stronger than that in MNA cured resins, which indicates that different chemical reactions occur as curing proceeds. Contrasting the W.L.F. type main relaxation $\alpha$, the $\beta$ relaxation is referred to the Arrhenius type as thermo-plastics (ref./5//6/). Figure 2 shows the frequency temperature dependence of the $\beta$ peak in BDA cured resins. The $\beta$ peak changes linearly owing to the Arrhenius expression, which predicts the peak temperature in the $\mathrm{MHz}$ range, $70-80^{\circ} \mathrm{C}$. Additional insight in $\mathrm{BDA}$ cured resins is provided by Figure 3 showing the values of longitudinal attenuation at $2 \mathrm{MHz}$ as a function of temperature. All the resins are in the glassy state over the observed temperature range. The attenuation in resins changes broadly and the peak temperatures are in good accordance with those predicted in Figure 2.

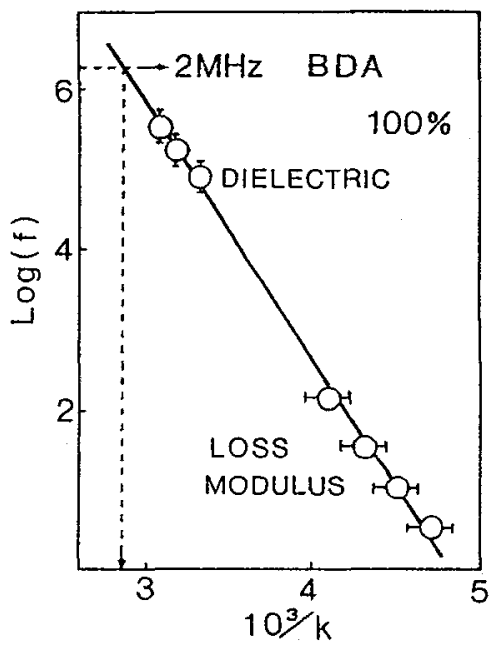

Fig.2 Temperature-Frequency correlation map of $\beta$ relaxation.

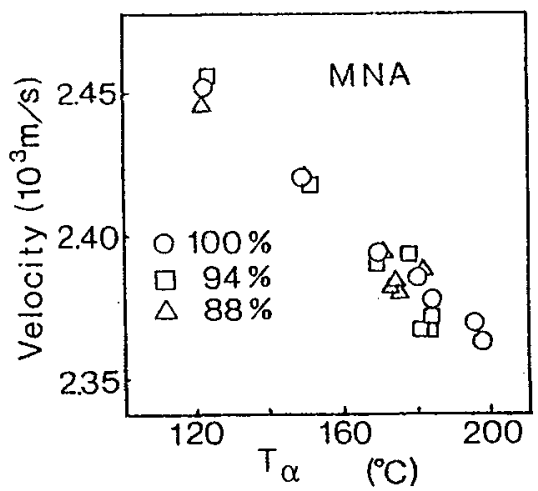

Fig.5 Dependence of longitudinal velocity on $\mathrm{T} \alpha$.

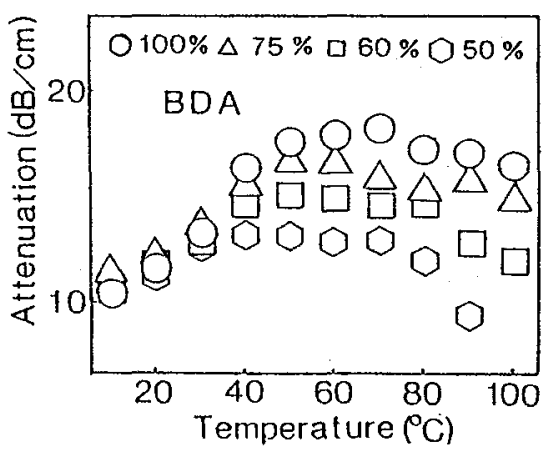

Fig.3 Dependence of longitudinal attenuation on temperature.

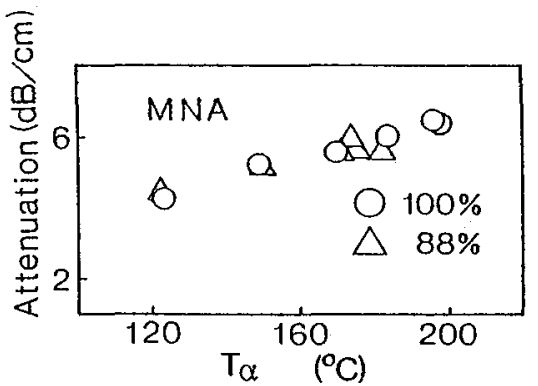

Fig.4 Dependence of longitudinal attenuation on $\mathrm{T} \alpha$.

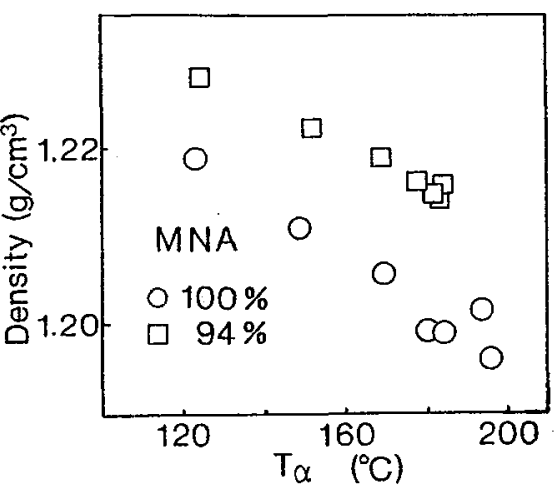

Fig.6 Dependence of room temperature density on $\mathrm{T} \alpha$. (at $23^{\circ} \mathrm{C}$ ) 
Figure 3 also shows the increase of attenuation due to the amount of curing agents. This reflects that the $\beta$ relaxation depends on the crosslinking process.

In the MNA cured resins, however, the $\beta$ peak couldn't be found in the observed frequency and temperature range. The longitudinal attenuations at $23^{\circ} \mathrm{C}$ are presented graphically in Figure 4 . The attenuation increased in those resins with high $\mathrm{T} \alpha$, i.e. those which are cured at high temperature and with nearly stoichiometric amount of curing agents. Figure 5 also shows the longitudinal wave velocity at $2 \mathrm{MHz}$, on T $\alpha$. The wave velocities decreased as T $\alpha$ increase. As mentioned above, T $\alpha$ directly reflects the heat resistance ability and shows the development of curing and crosslinking within the resin. From these results, it is predictable that the elasticity in the glassy state resins decreases as the curing and crosslinking proceeds, which also implies an effect of crosslinking on the elasticity of glassy state resins. Of course, this effect seems to have no connection with $\beta$ relaxation. These results, however, are quite opposite to the effect of crosslinking on the rubbery state resins, wherein the elasticity in the rubbery states resins have been reported to be proportional to the amount of crosslinks(ref./2/).

Table 2 Linear thermal coefficients of resins at $\mathrm{T} \alpha+10^{\circ} \mathrm{C}$.

(Resins cured with MNA of $100 \%$ )

\begin{tabular}{|c|cccccc|}
\hline & \multicolumn{5}{|c|}{ Curing Temperature } \\
\hline $\begin{array}{c}\text { Coefficients } \\
\left(10^{-4} / \mathrm{k}\right)\end{array}$ & $100^{\circ} \mathrm{C}$ & $120^{\circ} \mathrm{C}$ & $140^{\circ} \mathrm{C}$ & $160^{\circ} \mathrm{C}$ & $180^{\circ} \mathrm{C}$ & $200^{\circ} \mathrm{C}$ \\
\hline
\end{tabular}

Finally, room temperature measurements of resin density, plotted against $\mathrm{T} \alpha$, are provided in Figure 6. In the first mixture of these resins, the ratio of Epon 828 and MNA were the same. The room temperature density of cured resins is, however, strongly dependent on Ta. In addition, Table 2 lists the linear thermal coefficients of resins measured at $\mathrm{T} \alpha+10^{\circ} \mathrm{C}$. The coefficients vary inversely to the variation of curing temperature and the $T \alpha$ of the resins. These results therefore show the hindering effect of crosslinking in the shrinkage process of resins from the rubbery state to the glassy state. This effect of crosslinking can also be connected to the changes of elasticity during the glass transition process.

\section{CONCLUSION}

In the bisphenol A-based epoxy resins, both the amount of curing agent and the curing temperature control the process of crosslinking, which can be shown as the increase of the temperature of the main $\alpha$ relaxation. The advancement of crosslinking affects the strength of the $\beta$ relaxation in BDA cured resins. This relaxation also can be observed separated from the main relaxation in the $\mathrm{MHz}$ range. In addition, crosslinking seem to affect the shrinkage process of MNA cured resins, from the rubbery state to the glassy state. This is shown by the changes of the longitudinal wave velocity and attenuation in the glassy state resins.

\section{REFERENCES}

/1/ T.Murayama, J.P.Bell, J.Polym.Sci. A2,3,p.437(1970)

12/ A.V.Tobolsky, J.Polym.Sci. C,9,p.157(1965)

3/ L.Piche, F.Massines, G.lessard and A.Hamel, Proc.1987 Ultrasonics Symp.,IEEE cat\#87CH24927, p.1125

/4/ M.Ochi, S.Zhu and M.Shimbo, Polymer 27,p.1569(1986)

15/ M.B.M.Mangion and G.P.Johari, J.Polym.Sci. B,29,p.437(1991)

/6/ G.E.Roberts and E.F.T.White,"Relaxation processes in amorphous polymers" in physics of glassy polymers,edited by R.N.Haward,(Applied science publishers, London,1973) 